\title{
Gestão Municipal Consorciada: a experiência do Consórcio de Informática na Gestão Pública Municipal (CIGA)
}

\section{Municipal Management Consortium: the experience of the Computing Consortium in Municipal Public Management (CIGA)}

\author{
Gilsoni Lunardi Albino \\ Diretor Executivo, MBA em Gestão de Projetos no SENAI/SC \\ E-mail: gilsonilunardi@gmail.com \\ André Luiz Caneparo Machado \\ Auditor de Controle Externo, Graduando em Administração Pública na UDESC/ESAG \\ E-mail: andrecm@tce.sc.gov.br \\ Sílvia Maria Berté Volpato \\ Bibliotecária, Graduanda em Administração Pública na UDESC/ESAG \\ E-mail: silviaberte@hotmail.com
}

Resumo: O objetivo deste trabalho consiste em compreender a experiência do Consórcio de Informática na Gestão Pública Municipal (CIGA), de Santa Catarina. Com os aumentos das atribuições dos municípios em relação às políticas sociais descentralizadas, muitos municípios se articularam, constituindo consórcios públicos, com o objetivo de ampliar sua capacidade de gestão e disponibilidade de recursos para a otimização dos serviços prestados no gerenciamento integrado da gestão da tecnologia da informação, no oferecimento de informações compartilhadas das compras e serviços que venham a ser efetivados pelos entes consorciados. Os resultados mostram que, apesar das dificuldades, essa experiência trouxe um aprendizado para a cooperação em Santa Catarina, pois demonstra, principalmente, que os municípios juntos podem acessar um conjunto de informações e um conjunto que não seriam possíveis de forma individual.

Palavras-chave: Gestão pública municipal. Modelo federativo. Tecnologia da informação. Consórcios públicos. CIGA.

Abstract: The objective of this work is to understand the experience of the Computing Consortium in Municipal Public Management (CIGA), Santa Catarina. With the increase of municipalities' attributions in relation to decentralized social policies, many municipalities have articulated, constituting public consortia, with the objective of increasing their management capacity and 
ALBINO, Gilsoni L.; MACHADO, André L. C.; VOLPATO, Sílvia M. B. Gestão Municipal Consorciada: a experiência do Consórcio de Informática na Gestão Pública Municipal (CIGA)

availability of resources for the optimization of the services provided in the integrated management of the technology of the Information, in the offer of shared information of the purchases and services that will be effected by the consortium entities. The results show that, despite the difficulties, this experience has brought about a learning process for cooperation in Santa Catarina, since it demonstrates, mainly, that the municipalities together can access a set of information and a set that would not be possible in an individual way.

Keywords: Municipal public management. Federal model. Information Technology. Public consortia. CIGA.

\section{Introdução}

O sistema de reforma política e administrativa ampliou as possibilidades de gestão, remodelando, assim, o papel do Estado, que vem se omitindo de ser um executor de serviços e obras para ser um gestor. Como resultante dessa mudança, a descentralização de poder da esfera federal para o nível local intensificou o papel dos Municípios como entes federados e reorientou suas responsabilidades. Não obstante, essa mudança não foi acompanhada de capacitação adequada para a gestão local. Levando-se em conta as limitações estruturais, de recursos humanos e financeiros enfrentadas pela maioria dos Municípios, especialmente os pequenos, a instituição de parcerias e associações entre os Municípios, com vistas à troca de experiências, tem se mostrado uma tática executável.

No contexto desta abordagem, o interesse se volta para o ambiente da Administração pública, especificamente para os consórcios públicos nos municípios, estes, que até há pouco, ainda

que tentassem acompanhar a tecnologia da informação, não haviam implementado a alternativa até participarem do consorciamento, uma tendência em municípios brasileiros.

Os Consórcios Públicos consistem na união entre dois ou mais entes da federação (União, Estados e Municípios), sem fins lucrativos. O objeto dos consórcios públicos é a prestação de serviços públicos de modo associado. Isso quer dizer que dois ou mais entes federados poderão criar um consórcio para prestar um serviço público de interesse comum. Apresentam-se como institutos que podem trazer uma nova perspectiva no gerir da coisa pública e apresentam, inclusivamente, instrumentos inovadores na área da gestão pública, como podemos constatar, por exemplo, na

Revista Brasileira de Políticas Públicas e Internacionais, v.2, n.2, Dezembro/2017, pp. 119-134. 
ALBINO, Gilsoni L.; MACHADO, André L. C.; VOLPATO, Sílvia M. B. Gestão Municipal Consorciada: a experiência do Consórcio de Informática na Gestão Pública Municipal (CIGA)

ferramenta de gestão compartilhada das compras e serviços que venham a ser efetivados pelos entes consorciados.

No ano de 2007, foi constituído o Consórcio de Informática na Gestão Pública Municipal (CIGA), pela Federação Catarinense de Municípios (FECAM), com o propósito de desenvolver soluções para o aperfeiçoamento da gestão pública, usando a tecnologia da informação. Ressalte-se que o CIGA começou com 13 municípios associados, e atualmente o CIGA conta com 294 municípios consorciados, sendo 284 em Santa e já chegou a outros Estados, como Bahia, Acre, Paraíba, São Paulo, Paraná e Rio Grande do Sul, incluindo 6 capitais, levando soluções inovadoras, com custo acessível aos seus consorciados.

O CIGA tem por missão prover soluções tecnológicas para a melhoria da gestão pública. E, a visão de ser provedor de soluções tecnológicas de 100\% dos municípios catarinenses até 2017. A adoção da prática de consócio público pode trazer aperfeiçoamento da gestão pública, com o uso da tecnologia da informação.

O objetivo geral da pesquisa é descrever a estrutura do Consórcio de Informática na Gestão Pública Municipal (CIGA), como uma inovação da tecnologia de informação para os municípios catarinenses. O estudo justifica-se pela sua relevância no âmbito federativo. Com o respaldo da Lei $n^{\circ}$ 11.107/2005 (Brasil, 2005) e do Decreto n ${ }^{\circ}$ 6.017/2007 (Brasil, 2007) em vigor, que regularizou o tema Consórcios Públicos, despontou uma nova possibilidade de cooperação entre os entes para desempenharem suas competências constitucionais. Essa configuração de cooperação oportuniza aos municípios, principalmente os de pequeno porte, em que a receita é reduzida, se conectarem a um objetivo comum, o de prestar serviços públicos relevantes com qualidade. Destaca-se a incumbência da tecnologia da informação nos serviços. Essa união oportuniza o fortalecimento político e financeiro. Assim, o propósito é demonstrar que a cooperação e a coordenação podem resolver os problemas comuns a todos os entes e gerar efeitos positivos, criando em vez de rivalidade e competição, uma colaboração e um espírito de solidariedade de modo a assegurar um melhor equilíbrio federativo. O consórcio surge então como estrutura técnica capaz de demandar mais eficientemente os recursos, bem como possibilitar a ampliação da capacidade política dos Municípios a ele vinculado.

Revista Brasileira de Políticas Públicas e Internacionais, v.2, n.2, Dezembro/2017, pp. 119-134. 
ALBINO, Gilsoni L.; MACHADO, André L. C.; VOLPATO, Sílvia M. B. Gestão Municipal Consorciada: a experiência do Consórcio de Informática na Gestão Pública Municipal (CIGA)

A pesquisa irá primeiramente descrever sinteticamente o assunto, seguido da fundamentação teórica, discorrendo brevemente sobre a tecnologia da informação, a gestão pública no modelo federativo e a alternativa dos consórcios públicos e sua fiscalização e controle externo. Seguido dos procedimentos metodológicos adotados para a orientação desta pesquisa, e a apresentação dos resultados da pesquisa, encontrados a partir da análise do ambiente da organização e da prática do consórcio CIGA nos municípios de Santa Catarina.

\section{Fundamentação teórica}

A fundamentação teórica expõe o objeto da pesquisa inserido nos conhecimentos que versam sobre o tema proposto, e como tais conhecimentos permitirão responder à questão levantada por esta pesquisa. O processo de contextualização teórica sobre o tema iniciou-se com a consulta a fontes de informações, ou seja, em livros, artigos de periódicos e aos sites de instituições.

\subsection{Tecnologia da informação nas organizações}

Mudanças estão acontecendo de forma muito rápida no mercado. No âmbito da inovação tecnológica, salientam-se tópicos que repercutem nas organizações, como novas formas organizacionais, a inovação da Internet, a telemática, o campo da Informática e Computação.

Se a informação sempre fez parte da vida humana na função de ferramenta propulsora do avanço do conhecimento humano, hoje, com a Internet, assume sua natureza inovadora. Seu espaço quase infinito, sua natureza instantânea, seu sentido global e sua extensão infinita transcendem o alcance e o controle das pessoas, pois não obedecem a demarcações siderais, linguísticas, políticas e culturais, alcançando os mais diferentes aspectos da vida humana.

De acordo com Hunter (1998), a tecnologia está presente em todas as partes de nossa vida, desde operações bancárias e atendimento de saúde até tarefas do cotidiano, como cozinhar ou dirigir um carro. O autor acrescenta que a tecnologia tem contribuído para o desenvolvimento da administração do conhecimento, facilitando a satisfação das necessidades do homem, mesmo que em algum momento ela não resolva todos os problemas. A tecnologia é feita por pessoas, e sem o conhecimento dessas pessoas, ela não se consolida.

Revista Brasileira de Políticas Públicas e Internacionais, v.2, n.2, Dezembro/2017, pp. 119-134. 
ALBINO, Gilsoni L.; MACHADO, André L. C.; VOLPATO, Sílvia M. B. Gestão Municipal Consorciada: a experiência do Consórcio de Informática na Gestão Pública Municipal (CIGA)

Com isso, pontuam-se alguns campos comuns que estão transformando a vida das pessoas e das organizações, como aprendizado, conhecimento, visão (no sentido de estratégia), competição, liderança, recursos e inovações tecnológicas. São componentes estratégicos que, como salientou Drucker (1999), seriam necessários para as organizações enfrentarem o século XXI.

Uma vantagem importante dos sistemas informatizados é a de que, quando bem projetados, podem fornecer informações para ajudar no processo decisório e melhorar de maneira geral o processo de administração. A tecnologia proporciona serviços que antes não eram oferecidos por falta de meios adequados para fazê-lo. Pode-se citar, por exemplo, o serviço de execução e gestão associada de serviços públicos.

\subsection{A gestão pública no modelo federativo e a alternativa dos consórcios}

A partir da Constituição dos Estados Unidos do Brasil de 1891, que renovou o disposto no Decreto $\mathrm{n}^{\mathrm{o}}$ 1, de 15 de novembro de 1889 (BRASIL, 1989) em favor da adoção do regime republicano e do federalismo, todas as demais Constituições brasileiras repetiram o federalismo como forma de Estado.

As análises sobre o federalismo brasileiro favoreceram, nos últimos anos, os temas sobre a descentralização e a matéria do peso político e econômico da União, Estados e Municípios nas relações intergovernamentais.

O federalismo tornou-se peça-chave das políticas públicas brasileiras, principalmente depois da promulgação da Constituição de 1988. Segundo Abrucio, Sano e Sydow (2011), a constatação de que as prefeituras sozinhas não conseguem formular e implementar todas as políticas públicas tem norteado os municípios a procurar soluções cooperativas e em especial os consórcios.

De forma efetiva, procurou-se garantir a manutenção da lógica da federação com uma organização dupla do poder político, em que o Governo central e os Estados-membros foram dotados de autonomia política, administrativa e financeira com vista à arrecadação de renda própria. Assegurou-se, não obstante, ao Governo central soberania para representar todos nas relações externas com os demais países e entidades ou organismos internacionais. Apesar disso, deu-se a autonomia atribuída ao Estado membro, no transcorrer da história da recente política brasileira desde o acolhimento da vinda da Lei dos Consórcios Públicos. Com o crescimento da economia Revista Brasileira de Políticas Públicas e Internacionais, v.2, n.2, Dezembro/2017, pp. 119-134. 
ALBINO, Gilsoni L.; MACHADO, André L. C.; VOLPATO, Sílvia M. B. Gestão Municipal Consorciada: a experiência do Consórcio de Informática na Gestão Pública Municipal (CIGA)

brasileira e, consequentemente, das pressões sobre a Administração pública em anseio de eficácia e resultados, se alargaram e se remodelaram as iniciativas, algumas quase experimentais, de articulação entre os entes da federação.

\subsection{Consórcios públicos}

Os consórcios intermunicipais estão previstos no Brasil desde a Constituição de 1937 (BRASIL, 1937). Porém, sua sistematização e disseminação entre os gestores públicos começou a se consolidar apenas a partir da década de 1990, quando a descentralização das políticas públicas, resultada do desenho institucional que a Constituição de 1988 conferiu ao nosso federalismo, instituiu aos governos locais dilemas de coordenação e cooperação. A expectativa de firmar acordos entre os municípios, para que fossem resolvidos problemas de ação coletiva com resultados diretos sobre as políticas públicas, incorporou os consórcios intermunicipais na agenda de alguns governos locais que rejeitavam confundir sua autonomia política com o discurso da autossuficiência autárquica.

Segundo Batista et al. (2011), a descentralização tornou dinâmica a gestão dos municípios e esse contexto de novas e complexas atribuições motivou o surgimento dos consórcios públicos. A Emenda Constitucional 19/1998 acrescentou à redação do artigo 241 da Constituição Federal de 1988 (Brasil, 1988) a configuração dos consórcios públicos:

A União, os Estados, o Distrito Federal e os Municípios disciplinarão por meio de lei os consórcios públicos e os convênios de cooperação entre os entes federados, autorizando a gestão associada de serviços públicos, bem como a transferência total ou parcial de encargos, serviços, pessoal e bens essenciais à continuidade dos serviços transferidos.

Posteriormente foi publicada a Lei $n^{0}$ 11.107, de 06 de abril de 2005 (Brasil, 2005) que aborda normas gerais relativamente a contratações de consórcios públicos.

O desenvolvimento de consórcios intermunicipais se deu, principalmente, no setor de saneamento, instalação de infraestrutura de energia elétrica, construção de estradas e atividades relacionadas à promoção de saúde pública.

Revista Brasileira de Políticas Públicas e Internacionais, v.2, n.2, Dezembro/2017, pp. 119-134. 
ALBINO, Gilsoni L.; MACHADO, André L. C.; VOLPATO, Sílvia M. B. Gestão Municipal Consorciada: a experiência do Consórcio de Informática na Gestão Pública Municipal (CIGA)

Para constituir um consórcio a lei estabelece a obrigatoriedade da criação de uma pessoa jurídica, para que possa assumir direitos e obrigações. Os consórcios públicos constituem-se numa associação pública com personalidade jurídica de direito público e de natureza autárquica ou como pessoa jurídica de direito privado sem fins econômicos, de acordo com o Art. $2^{\circ}$, I, do Dec. 6.017/07 (Brasil, 2007).

Os Municípios, os Estados e a União quando se consorciam, delegando competências, não as renunciam. Participando do Conselho de Administração e da Assembleia Geral do consórcio, eles as supervisionam. O consórcio público constitui-se como expressão do exercício das autonomias dos entes federados consorciados (Observatório, 2016).

\subsubsection{Fiscalização e controle externo dos consórcios públicos}

Pelas colocações contidas nos Arts. 70 e 71 da CF/1988 (Brasil, 1988), tem-se que é atribuição precípua do Congresso Nacional, com o auxílio do Tribunal de Contas, a execução do chamado controle externo. Nesses dispositivos, encontram-se a natureza e os fins da atividade a ser exercida pelos Tribunais de Contas, o tipo de controle ou a sistemática de atuação, quem são os entes objeto ou alvo da fiscalização, assim como as suas atribuições ou competências.

Para fins de prestação de contas anual serão utilizadas as normas gerais de Direito Financeiro estabelecidas pela lei Federal n 4320/64 (Brasil, 1964), quando não existir legislação ou norma legal específica. As formas mais comuns de obtenção de recursos financeiros são: Contrato de rateio, Contrato administrativo, Convênios e Contratos de programas. Assim, devem ser observados os critérios de prestação de contas pertinentes a cada modalidade. Sendo que os agentes públicos responsáveis pela gestão do Consórcio não respondem pessoalmente pelas obrigações contraídas pelo Consórcio, mas respondem por todos os atos praticados em desconformidade com a lei ou disposições dos respectivos estatutos (Brasil, 1005).

O Tribunal de Contas de Santa Catarina (TCE/SC) faz parte do Sistema Tribunal de Contas do Brasil. É o órgão responsável pelo controle externo das atividades das entidades tanto da Administração direta como da indireta. A sua Instrução Normativa N.TC-0020/2015 (Santa

Revista Brasileira de Políticas Públicas e Internacionais, v.2, n.2, Dezembro/2017, pp. 119-134. 
ALBINO, Gilsoni L.; MACHADO, André L. C.; VOLPATO, Sílvia M. B. Gestão Municipal Consorciada: a experiência do Consórcio de Informática na Gestão Pública Municipal (CIGA)

Catarina, 2015), estabelece critérios para organização e apresentação da prestação de contas anual, normas relativas à remessa de dados, informações e demonstrativos por meio eletrônico.

\subsubsection{Legislação aplicada aos consórcios públicos}

As principais legislações relacionadas aos consórcios públicos são a Constituição Federal de 1988, o Decreto n 6.017, de 17 de janeiro de 2007 (Brasil, 2007), a Instrução Normativa N.TC0020/2015 (Santa Catarina, 2015), a Lei n 4.320, de 17 de março de 1964 (Brasil, 1964), a Lei Complementar $\mathrm{n}^{\mathrm{o}}$ 101, de 4 de maio de 2000 (Brasil, 2000), a Lei ${ }^{\circ}$ 11.107, de 6 de abril de 2005 (Brasil, 2005), o Manual de Receitas Públicas da Secretaria do Tesouro Nacional, a Portaria ${ }^{\circ} 42$, de 14 de abril de 1999 (Brasil, 1999), a Portaria nº 60, de 12 de dezembro de 2005 (Brasil, 2005) e a Portaria Interministerial no 163, de 04 de maio de 2001 (Brasil, 2001).

Assim, as possibilidades para a atuação dos consórcios públicos são bastante abrangentes, não obstante seja necessária a observância dos preceitos expressos na Lei e na Constituição, para que se tornem viáveis e executáveis na prática.

\section{Método e procedimentos de pesquisa}

O objetivo deste estudo é investigar os consórcios públicos como uma configuração de cooperação do federalismo. Para tanto, preliminarmente, a tentativa de resposta às questões que orientaram este artigo é buscar, a partir da fundamentação teórica e da consulta à legislação brasileira, o cenário sobre esse arranjo institucional, investigando sua identificação, suas leis e como o território exerce base para influenciar as ações dessa instituição.

Com o intuito de conhecer a situação do Consórcio de Informática na Gestão Pública Municipal (CIGA), procedeu-se a consultas em fontes oficiais e a realização de entrevista com o Diretor do Consórcio, envolvido com o objeto de estudo. Assim, o objetivo final foi sistematizar as informações e argumentos, a fim de contribuir com o estudo dos consórcios públicos e sua utilização no país.

A pesquisa qualitativa é considerada essencialmente de campo, porquanto nas ciências sociais a maioria dos estudos está relacionada a fenômenos de grupos ou sociedades, razão pela qual o investigador deve atuar onde se desenvolve o objeto de estudo.

Revista Brasileira de Políticas Públicas e Internacionais, v.2, n.2, Dezembro/2017, pp. 119-134. 
ALBINO, Gilsoni L.; MACHADO, André L. C.; VOLPATO, Sílvia M. B. Gestão Municipal Consorciada: a experiência do Consórcio de Informática na Gestão Pública Municipal (CIGA)

Sendo a finalidade do trabalho compreender a experiência do Consórcio de Informática na Gestão Pública Municipal (CIGA), de Santa Catarina, considerou-se adequado utilizar o estudo de caso. Para Yin (2001), o estudo de caso tem uma utilização maior em estudos exploratórios e descritivos, mas também pode ser importante para fornecer respostas relativas a causas de determinados fenômenos. Triviños (1987) define estudo de caso como uma categoria de pesquisa cujo objeto é uma unidade que se analisa profundamente. Tendo como objetivo aprofundar a descrição de determinada realidade.

Neste trabalho, foi utilizado o método de pesquisa, de cunho qualitativo, que teve como objetivo descrever a estrutura do Consórcio de Informática na Gestão Pública Municipal (CIGA), como uma inovação da tecnologia de informação para os municípios catarinenses.

\section{Apresentação e discussão dos resultados da pesquisa}

Para a composição deste capítulo foi contextualizada a unidade organizacional, representada neste trabalho pelo Consórcio de Informática na Gestão Municipal (CIGA). O texto foi construído com base em documentos, estatuto, sítios da Internet, bem como notas de campo com dados da gestão estratégica do mesmo.

O Consórcio de Informática na Gestão Pública Municipal (CIGA) é um consórcio público, fundado em 2007 por iniciativa da Federação Catarinense de Municípios (FECAM), com o propósito de desenvolver soluções para o aperfeiçoamento da gestão pública, com o uso da tecnologia da informação.

O CIGA é pessoa jurídica de direito público, sob a forma de associação pública, devendo reger-se pelas normas da Constituição da República Federativa do Brasil (BRASIL, 1988), da Lei Federal nº 11.107, de 6 de abril de 2005 (Brasil, 2005), do Contrato de Consórcio, pelo Regimento Interno (Ciga, 2009) e pela regulamentação que vier a ser adotada pelos seus órgãos competentes.

O objetivo do CIGA é desenvolver ferramentas de governança eletrônica, por meio do emprego de tecnologias da informação e comunicação (TIC). Visa ao desenvolvimento, implantação, capacitação, manutenção e suporte de sistemas de tecnologia da informação e comunicação que permitam o diálogo entre governo e cidadão, o aprimoramento da gestão pública,

Revista Brasileira de Políticas Públicas e Internacionais, v.2, n.2, Dezembro/2017, pp. 119-134. 
ALBINO, Gilsoni L.; MACHADO, André L. C.; VOLPATO, Sílvia M. B. Gestão Municipal Consorciada: a experiência do Consórcio de Informática na Gestão Pública Municipal (CIGA)

a transparência no poder público e a inclusão digital, resultando em atendimento das demandas da sociedade.

Atualmente o CIGA conta com 294 municípios consorciados. Prover soluções tecnológicas para a melhoria da gestão pública é a sua missão. Tem por visão ser provedor de soluções tecnológicas de $100 \%$ dos municípios catarinenses até 2017. Até o momento são 380 contratos e 760 programas disponibilizados. Seus valores são (Ciga, 2016): Economicidade; Inovação; Eficiência; Transparência e o Cumprimento dos princípios da Administração pública.

O CIGA preza pela agilidade no atendimento aos usuários e pela transparência pública. Tem por objetivo contribuir com a gestão por meio da economia de recursos, melhoria nos serviços de tecnologia com custo reduzido de contratação agregado à melhoria da gestão e dos processos.

Para motivar os municípios a participar do CIGA, a FECAM e as Associações de Municípios realizam reuniões e eventos nos quais divulgam os objetivos e vantagens do CIGA e convida os municípios a participar.

No início o CIGA foi fundado por somente 13 municípios que solenizaram o Protocolo de Intenções, ficando autorizado o ingresso dos demais municípios catarinenses. A FECAM percebeu a necessidade de oferecer aos municípios ferramentas de internet que proporcionassem soluções aos problemas e necessidades nesta área.

O CIGA atua desenvolvendo ferramentas ou contratando no mercado aquelas ferramentas que não pode desenvolver e as coloca a serviço dos municípios participantes. Dentre os Fatores destacados na explicação sobre a formação do arranjo, está a necessidade de tecnologias de informação com custos baixos além da autonomia para os municípios na gestão das ferramentas por ele gerenciadas.

Quanto aos principais protagonistas que atuaram no processo de criação do CIGA, constatase que foram a FECAM, por incentivar a experiência em consorciamento, por meio do seu centro de tecnologia, que identificou a necessidade deste tipo de arranjo.

O CIGA foi reconhecido pelo Tribunal de Contas do Estado de Santa Catarina, assim como outros consórcios públicos atuantes no Estado. O CIGA teve, na sua base legal, o arranjo formalizado após a promulgação da Lei no 11.107/2005 (Brasil, 2005), sobre consórcio público de direito público e do Decreto Federal nº 6.017/2007 (Brasil, 2007).

Revista Brasileira de Políticas Públicas e Internacionais, v.2, n.2, Dezembro/2017, pp. 119-134. 
ALBINO, Gilsoni L.; MACHADO, André L. C.; VOLPATO, Sílvia M. B. Gestão Municipal Consorciada: a experiência do Consórcio de Informática na Gestão Pública Municipal (CIGA)

Os recursos financeiros para gestão do CIGA são provenientes dos recursos repassados em sua maior parte pelos Municípios, mais ele pode receber também recursos da União, dos Estados; dos recursos oriundos de convênios, contratos e/ou parcerias com outras entidades; dos recursos de prestações de serviços técnicos; dos recursos eventuais que lhes forem repassados por entidades públicas e privadas; das doações e transferências em geral; do produto de operações de crédito ou aplicações financeiras.

O consórcio público está sujeito à fiscalização financeira, organizacional, contábil, operacional e patrimonial dos Tribunais de Contas, do Poder legislativo, dos entes consorciados, da Assembleia Geral do consórcio, entre outros.

Quanto ao arranjo do ponto de vista institucional, o consórcio tem aumentado seu grau de autonomia em relação à FECAM, pois atualmente o CIGA já possui estrutura própria de operação para buscar o alcance de seus objetivos. Com relação aos municípios consorciados, a dependência é elevada, uma vez que o CIGA depende do que arrecada dos seus membros. Sendo que em 2014, dos seus então 235 municípios consorciados, a arrecadação está na ordem de R\$ 1.945.055,33. Em 2015, já com seus 283 municípios consorciados, a arrecadação foi de R \$ 3.470.549,72.

Com relação aos mecanismos de transparência, as ações e documentos do CIGA estão publicados no seu site e no Diário Oficial dos Municípios. Além deste expediente, as assembleias são ambientes de divulgação e publicização das ações do CIGA.

Uma maneira de averiguar a efetividade dos resultados do CIGA pode ser observada através do serviço de publicação dos atos oficiais municipais por meio do Diário Oficial dos Municípios de Santa Catarina (DOM/SC), no comparativo da tabela abaixo:

Revista Brasileira de Políticas Públicas e Internacionais, v.2, n.2, Dezembro/2017, pp. 119-134. 
ALBINO, Gilsoni L.; MACHADO, André L. C.; VOLPATO, Sílvia M. B. Gestão Municipal Consorciada: a experiência do Consórcio de Informática na Gestão Pública Municipal (CIGA)

Tabela 1: Comparativo da economicidade do DOM/SC em relação aos meios tradicionais de publicação nos anos de 2014 e 2015

\begin{tabular}{|c|c|c|c|c|}
\hline \multicolumn{5}{|c|}{ (Valores expressos em milhões de reais) } \\
\hline Ano & Atos publicados & $\begin{array}{c}\text { Custo } \\
\text { convencional } \\
\text { estimado }\end{array}$ & $\begin{array}{c}\text { Custo publicação } \\
\text { eletrônica CIGA }\end{array}$ & $\begin{array}{c}\text { Economia anual } \\
\text { estimada aos } \\
\text { municípios } \\
\text { consorciados }\end{array}$ \\
\hline 2014 & 200.515 & 40,1 & 0,7 & 39,4 \\
\hline 2015 & 233.508 & 46,7 & 1,0 & 45,7 \\
\hline
\end{tabular}

Fonte: Relatórios de atividades do CIGA 2014 e 2015

Dentre outros pontos positivos da atuação do CIGA, a economia de escala como o principal fator de seus projetos, seguido dos aspectos relacionados ao aprimoramento da gestão pública e transparência que a implementação do DOM gera, e também aspectos relacionados ao incremento da arrecadação dos programas tributários. A simplificação de adesão aos programas tem sido outro facilitador dos projetos do CIGA e do dia a dia das prefeituras.

O CIGA atua na área de tecnologia da informação e tem tido excelente resultado em projetos em nuvem e sistemas que podem ser implementados com baixa complexidade para o usuário.

Internamente o maior desafio tem sido as licitações, com baixo interesse para compras pequenas (para o CIGA em si) e certa dificuldade em compras de grande escala para os consorciados por envolver editais de elevada complexidade técnica, jurídica e econômica.

Outra dificuldade observada na gestão do CIGA é a questão de um grande número de gestores espalhados geograficamente, que geram dificuldades de reunir a assembleia geral.

Quanto a participação do cidadão, do Estado e da União no CIGA, percebe-se que a interação com o cidadão é indireta, por meio do uso que os mesmos fazem do DOM que é totalmente aberto, sem exigir qualquer cadastro para o acesso às informações que desejar.

Sobre aspectos político-partidários, percebe-se baixa ingerência, um dos motivos vem da questão da grande diversidade partidária dos consorciados e do conselho de administração do CIGA.

Revista Brasileira de Políticas Públicas e Internacionais, v.2, n.2, Dezembro/2017, pp. 119-134. 
ALBINO, Gilsoni L.; MACHADO, André L. C.; VOLPATO, Sílvia M. B. Gestão Municipal Consorciada: a experiência do Consórcio de Informática na Gestão Pública Municipal (CIGA)

No CIGA, como outros consórcios, produz grandes impactos na gestão associada, mas, na área de informática esses resultados podem ser exponenciais em virtude de que sistemas geralmente possuem um custo mínimo que fica praticamente inalterado a partir de um ponto. Como não visam lucros, os projetos desenvolvidos internamente podem representar economia de mais de 95\% do valor de mercado. Mesmo com softwares licitados de terceiros a economia pode chegar a 75\%, porém aumenta o nível de complexidade relativo a licenças, gestão dos programas e capacitação.

O CIGA fornece atualmente seis programas aos seus consorciados, possui como órgão máximo da gestão a Assembleia Geral formada por gestores, que elegem o conselho de Administração e Fiscal.

O quadro de pessoal é formado por 17 empregados, sendo 1 diretor, dois gerentes contratados por livre nomeação e outros 14 empregados públicos contratos por concurso públicos no regime da CLT.

\section{Considerações finais}

A Constituição Federal de 1988 aglutinou complexidade ao desenho federativo brasileiro, reconhecendo o município como ente federado. Essa ação foi acompanhada por destacada descentralização de políticas públicas, sem os devidos recursos financeiros para atender as novas demandas, neste contexto diversas experiências de consórcios foram sinalizadas por municípios no país e hoje esse é um instrumento de numerosa utilização. As delimitações institucionais e jurídicas das caracterizações utilizadas pelos municípios, no entanto, ocasionaram a aprovação da Emenda Constitucional n 19/1998 (Brasil, 1998) que instituiu os consórcios públicos e a gestão associada de serviços públicos.

Assim, a escassez de recursos, e a necessidade crescente das populações por bens e serviços públicos, fizeram com que diversos Municípios extrapolassem seus limites territoriais, e se aliassem com os seus vizinhos, formando os consórcios intermunicipais.

Segundo Silva e Vieira (2016) até a lei de criação dos consórcios públicos, não havia no ordenamento jurídico nacional um instrumento adequado para a articulação e cooperação de políticas públicas federativas de responsabilidade compartilhada. Para os autores, esta ação

Revista Brasileira de Políticas Públicas e Internacionais, v.2, n.2, Dezembro/2017, pp. 119-134. 
ALBINO, Gilsoni L.; MACHADO, André L. C.; VOLPATO, Sílvia M. B. Gestão Municipal Consorciada: a experiência do Consórcio de Informática na Gestão Pública Municipal (CIGA)

fortalece o federalismo como instrumento estratégico no desenvolvimento econômico e social de maneira integrada e sustentável, dando, com isso, outra dimensão às políticas públicas.

Os gestores públicos municipais, ao se unirem em consórcio com a participação dos Poderes Legislativos envolvidos, dispõem a seu favor limites maiores, de acordo com a Lei n ${ }^{\circ}$ 8.666/1993 (Brasil, 1993), o que permite obter com segurança vantagens expressivas para materializar a aquisição dos objetos e serviços.

O CIGA, consórcio público constituído em Santa Catarina está se mostrando uma alternativa viável para gerir com economicidade e eficiência os recursos públicos disponíveis para os municípios, considerando inclusive as flexibilizações aprovadas na forma de contratações, realizadas por essas entidades.

O CIGA demonstra os benefícios resultados, como a união de municípios concretizada em serviços públicos na tecnologia de informação que oferecem à população, como os sistemas apresentados, com ênfase para a economia de escala como o principal fator nos projetos em que atua.

Com relação aos aspectos mais problemáticos da experiência estudada, aponta-se especialmente a dificuldade na gestão do CIGA em reunir um grande número de gestores espalhados geograficamente, e que isso gera dificuldades para a assembleia geral. Relevantes também são os problemas estruturais na questão tecnológica do Brasil.

Uma vez que a articulação de consórcios intermunicipais atende a uma lógica por um lado de descentralização na prestação de serviços públicos e por outro de integração para maior economia de custos, a preocupação gerencialista de eficiência está bem presente na experiência estudada e tem assegurado a qualidade na prestação de serviços.

Revista Brasileira de Políticas Públicas e Internacionais, v.2, n.2, Dezembro/2017, pp. 119-134. 
ALBINO, Gilsoni L.; MACHADO, André L. C.; VOLPATO, Sílvia M. B. Gestão Municipal Consorciada: a experiência do Consórcio de Informática na Gestão Pública Municipal (CIGA)

\section{Referências}

Abrucio, Fernando Luiz; Sano, Hironobu; Sydow, Cristina Toth (2011). Radiografia do associativismo territorial brasileiro: tendências, desafios e impactos sobre as Regiões Metropolitanas. In: Klink, J. (Org.). Governança das metrópoles. São Paulo: Annablume. Disponível em: <http://igepp.com.br/uploads/ebook/igepp_abrucio_f._sano_h.__sydow_c._radiografia_do_asso ciativismo_territorial_brasileiro.pdf $>$. Acesso em: 28 ago. 2016.

Batista, Sinoel (2011). O papel dos prefeitos e das prefeitas na criação e na gestão dos consórcios públicos. Brasília: Caixa Econômica Federal. 115 p. (Guia de Consórcios Públicos - Caderno; v. 1). Disponível em: <http://www.portalfederativo.gov.br/consorcios-publicos/legislacaodocumentos/guia_consorcios_publicos_vol1.pdf>. Acesso em: 14 ago. 2016.

Brasil (1988). Constituição da República Federativa do Brasil de 1988. Disponível em: <http://www.planalto.gov.br/ccivil_03/constituicao/constitui\%C3\%A7ao.htm>. Acesso em: 20 ago. 2016.

Brasil (1889). Decreto $n^{o} 1^{o}$, de 15 de novembro de 1889. Proclama provisoriamente e decreta como forma de governo da Nação Brasileira a República Federativa, e estabelece as normas pelas quais se devem reger os Estados Federais. Disponível em: <http://www.planalto.gov.br/ccivil_03/decreto/1851-1899/D0001.htm>. Acesso em: 21 ago. 2016.

Brasil. Decreto $n^{o}$ 6.017, de 17 de janeiro de 2007. Regulamenta a Lei $\mathrm{n}^{0} 11.107$, de 6 de abril de 2005, que dispõe sobre normas gerais de contratação de consórcios públicos. Disponível em: <http://www.planalto.gov.br/ccivil_03/_ato2007-2010/2007/decreto/d6017.htm>. Acesso em: 07 set. 2016.

Brasil (1998). Emenda constitucional $n^{\circ}$ 19, de 04 de junho de 1998. Brasília: Casa Civil, 1998. Disponível em: $<$ http://www.planalto.gov.br/ccivil_03/constituicao/Emendas/Emc/emc19.htm\#art24>. Acesso em: 21 ago. 2016.

Brasil (2005). Lei $n^{o}$ 11.107, de 6 de abril de 2005. Dispõe sobre normas gerais de contratação de consórcios públicos e dá outras providências. Brasília: 2005. Disponível em: <http://www.planalto.gov.br/ccivil_03/_ato2004-2006/2005/lei/l11107.htm>. Acesso em: 14 ago. 2016.

Ciga (2016). Consórcio de Informática na Gestão Pública Municipal. Florianópolis. Disponível em: <https://ciga.sc.gov.br/quem-somos/>. Acesso em: 14 ago. 2016.

Ciga (2016). Consórcio de Informática na Gestão Pública Municipal. Diário Oficial dos Municípios de Santa Catarina. Disponível em: <htps://diariomunicipal.sc.gov.br/site/>. Acesso em: 28 ago. 2016.

Ciga (2009). Consórcio de Informática na Gestão Pública Municipal. Regimento interno. Disponível em: <https://ciga.sc.gov.br/wp-content/uploads/2015/04/regimento_interno_ciga.pdf>. Acesso em: 15 ago. 2016.

Revista Brasileira de Políticas Públicas e Internacionais, v.2, n.2, Dezembro/2017, pp. 119-134. 
ALBINO, Gilsoni L.; MACHADO, André L. C.; VOLPATO, Sílvia M. B. Gestão Municipal Consorciada: a experiência do Consórcio de Informática na Gestão Pública Municipal (CIGA)

Ciga (2016). Consórcio de Informática na Gestão Pública Municipal. Relatório de atividades e prestação de contas e Plano de trabalho e proposta orçamentária. Disponível em: <https://ciga.sc.gov.br/wp-content/uploads/2017/01/Relatorio-CIGA-2016-Plano-de-Trabalho2017.pdf>. Acesso em: 31 jan. 2017.

Drucker, Peter Ferdinand (1999). Administrando em tempos de grandes mudanças. São Paulo: Pioneira.

Federação Catarinense de Municípios (Fecam) (2016). Florianópolis. Disponível em: <http://www.fecam.org.br/>. Acesso em: 20 ago. 2016.

Felippim, Eliane Salete; Arucio, Fernando Luiz (2011). A Federação Catarinense de Municípios (FECAM) e o Fomento de Consórcios Públicos: explicações para a originalidade do caso. ENCONTRO NACIONAL DOS PROGRAMAS DE PÓS-GRADUAÇÃO EM ADMINISTRAÇÃO. Anais eletrônicos. Disponível em: <http://www.anpad.org.br/admin/pdf/APB2497.pdf>. Acesso em: 16 ago. 2016.

Gil, Antonio Carlos (2008). Como elaborar projetos de pesquisa. 4. ed. São Paulo: Atlas, 2008.

Hunter, R. (1998). Tecnologia da informação: as razões e os meios da administração do conhecimento. Exame, São Paulo, v. 32, n. 18, p. 26, ago.

Observatório dos Consórcios Públicos e do Federalismo (2016). Consórcios Públicos. Disponível em: <http://www.ocpf.org.br/quem-somos/parceiros/>. Acesso em: 6 ago. 2016.

Silva, Fabiana da; Vieira, Ricardo Stanziola (2016). Consórcios públicos: uma possível alternativa para o desenvolvimento territorial sustentável em Santa Catarina. Disponível em: $<$ http://docplayer.com.br/11378890-Consorcios-publicos-uma-possivel-alternativa-para-odesenvolvimento-territorial-sustentavel-em-santa-catarina.html> . Acesso em: 20 ago. 2016.

Trivinõs, A. N. S (1987). Introdução à pesquisa em ciências sociais: a pesquisa qualitativa em educação. São Paulo: Atlas.

YIN, Robert K (2001). Estudo de caso: planejamento e métodos. 2. ed. Porto Alegre: Bookman.

Revista Brasileira de Políticas Públicas e Internacionais, v.2, n.2, Dezembro/2017, pp. 119-134. 